\title{
The pace-of-life: A sex-specific link between metabolic rate and life history in bean beetles
}

\author{
Göran Arnqvist $^{1}$ (D) | Biljana Stojković ${ }^{2,3}$ | Johanna L. Rönn ${ }^{1}$ | Elina Immonen ${ }^{1}$
}

\author{
${ }^{1}$ Animal Ecology, Department of Ecology \\ and Genetics, Evolutionary Biology \\ Centre, Uppsala University, Uppsala, Sweden \\ ${ }^{2}$ Department of Evolutionary Biology, Institute \\ for Biological Research, University of Belgrade, \\ Belgrade, Serbia \\ ${ }^{3}$ Institute of Zoology, Faculty of Biology, \\ University of Belgrade, Belgrade, Serbia

\section{Correspondence \\ Göran Arnqvist \\ Email: goran.arnqvist@ebc.uu.se}

\section{Funding information} \\ Vetenskapsrådet, Grant/Award Number: \\ 621-2014-4523; European Research \\ Council, Grant/Award Number: GENCON \\ AdG-294333; Serbian Ministry of Education, \\ Science and Technological Development, \\ Grant/Award Number: 173007 \\ Handling Editor: Craig White
}

\begin{abstract}
1. Metabolic rate (MR) is a key functional trait simply because metabolism converts resources into population growth rate. Yet, our empirical understanding of the sources of within species variation in MR, as well as of its life history and ecological correlates, is rather limited. Here, we assess whether MR lies at the root of a syndrome of correlated rate-dependent life-history traits in an insect.

2. Selection for early $(E)$ or late $(L)$ age-at-reproduction for $>160$ generations in the bean beetle Acanthoscelides obtectus has produced beetles that differ markedly in juvenile development, body size, fecundity schedules, ageing and life span. Here, we use micro-respirometry to test whether this has been associated with the evolution of age- and sex-specific metabolic phenotypes.

3. We find that mass-specific MR is $18 \%$ higher in $E$ lines compared to $L$ lines and that MR decreases more rapidly with chronological, but not biological, age in $E$ lines. Males, under sexual selection to "live-fast-die-young", show 50\% higher MR than females and MR decreased more rapidly with age in males.

4. Our results are consistent with a central role for MR for the divergence in "paceof-life" seen in these beetles, supporting the view that MR lies at the root of ecologically relevant life-history trait variation within species.
\end{abstract}

\section{KEYWORDS}

ageing, Bruchinae, functional traits, metabolism, mitochondria, OXPHOS, respiratory quotient, senescence

\section{1 | INTRODUCTION}

Among all functional traits studied in ecology, metabolic rate (MR) has a uniquely central role (Brown, Gillooly, Allen, Savage, \& West, 2004). This is simply because MR ultimately determines the rate at which resources are converted into population growth rate, an effect mediated primarily through vital rates, rate dependent life-history traits, body size and life span (Burton, Killen, Armstrong, \& Metcalfe, 2011; McGill, Enquist, Weiher, \& Westoby, 2006). Yet, our empirical understanding of the sources of within species variation in MR is limited (Arnqvist et al., 2010; Nespolo \& Franco, 2007) as are our appreciation of its life-history trait correlates and ecological consequences (Burton et al., 2011). The pace-of-life syndrome (POLS) hypothesis suggests that variation in rate dependent physiological traits (e.g. MR) generates the often observed syndrome of covarying life-history traits with important ecological ramifications (Martin, Hasselquist, \& Wikelski, 2006; Réale et al., 2010; Ricklefs \& Wikelski 2002; Wikelski, Spinney, Schelsky, Scheuerlein, \& Gwinner et al. 2003) but a key role for MR has very rarely been explored (Careau, Bininda-Emonds, Thomas, Réale, \& Humphries, 2009; Galliard, Paquet, Cisel, \& Montes-Poloni, 2013). Under POLS, variation in MR across populations could determine intraspecific variation in population productivity, reproductive schedules and life span. Conversely, local adaptation to distinct mortality regimes could have important feedback effects on ecological dynamics, through MR-mediated effects on life span and other 
rate-dependent life-history traits (Bassar et al., 2010; Reznick, 2013; Reznick, Bryant, Roff, Ghalambor, \& Ghalambor, 2004; Schoener, 2011).

Here, we test for the predicted central role of MR under POLS, using a set of bean beetle (Acanthoscelides obtectus, Coleoptera, Bruchinae) selection lines. These lines have been selected for $>160$ generations for reproduction early (E) or late (L) in adult life (Tucić, Stojković, Gliksman, Milanović, \& Šešlija, 1997; Tucić et al., 1996) and now show dramatic differences in life-history traits. Most importantly, $L$ line beetles live much longer: the average life span of virgin females is 10.3 days in $E$ lines (rate of senescence $=0.65$ ), 25.6 days in $L$ lines (rate of senescence $=0.23$ ) and 14.6 days in the base population (Đorđević, Savković, Lazarević, Tucić, \& Stojković, 2015; Stojković \& Savković, 2011; Stojković, Šešlija Jovanović, Tucić, \& Tucić, 2010). Further, E line beetles show a more rapid egg-adult development time and are smaller than beetles from the $L$ lines. The reproductive schedules are also markedly different, with $\mathrm{E}$ line beetles laying many more eggs early in life (Tucić et al., 1996; Tucić, Šešlija, \& Stankovic, 2004). In effect, $E$ line beetles exhibit the hallmarks of a fast pace-of-life (POL) and $L$ lines those of a slow POL. Although the mitochondrial metabolic machinery (i.e. the activities of the complexes in the electron transport chain) has evolved divergently in $E$ and $L$ lines, in part as a result of mitochondrial genetic effects (Đorđević et al., 2017; Stojković et al., 2017), it is not known whether organismal MR plays the predicted central role in the life-history trait variation seen.

The exact nature of this prediction, however, needs to be considered more closely. Although metabolism clearly plays an important functional role in life history trade-offs, comparative data have actually unveiled both negative and positive associations between MR and life span. In fact, the precise role that MR plays for ageing is not entirely clear (Burton et al., 2011; Speakman, 2005). Rubner (1908) noted that animals living at a faster rate will also live shorter lives if the total lifetime energy expenditure is constant, in what became known as the "rate of living" (ROL) hypothesis (Pearl, 1928). Harman (1956) instead suggested that high MR may cause increased production of reactive oxygen species (ROS) in mitochondria, in turn causing intracellular molecular damage and thus accelerating ageing. The general validity of this "free radical" hypothesis of ageing has, however, been questioned (Brand, 2000; Holzerová \& Prokisch, 2015; Lane, 2011; Selman, Blount, Nussey, \& Speakman, 2012).

In terms of within-species variation, individuals commonly vary both in terms of energy allocation and energy acquisition. Two hypotheses predict how such variation may generate covariation between MR and life-history traits (Boratyński \& Koteja, 2010; Burton et al., 2011; Maklakov, Rowe, \& Friberg, 2015). First, low MR may be associated with a slow POL if a low MR serves to economise the use of energy, thus leaving more resources available for the allocation of finite resources later in life. Thus, this hypothesis stresses the costs of maintaining the metabolic machinery and assumes that individuals then vary in the allocation of available energy resources. Second, high MR may instead be associated with a slow POL if greater metabolic machinery enables greater assimilation of energy for both cellular repair mechanisms and other forms of maintenance. This hypothesis thus sees the metabolic machinery as primarily generating allocable resources, such that individuals differ primarily in energy acquisition. Unfortunately, the paucity of relevant studies makes it very difficult to evaluate the extent to which within-species variation in MR represents variation in allocation and acquisition, respectively (Burton et al., 2011; Speakman, 2005; Speakman et al., 2004). Positive association between MR and longevity/survival has been reported in mice and voles, but were assumed to reflect ROS production (Speakman et al., 2004) and thermogenic capacity (Jackson, Trayhurn, \& Speakman, 2001). Artacho and Nespolo (2009) documented a negative association between MR and survival in snails, which has also been found in squirrels (Boratyński, Koskela, Mappes, \& Oksanen, 2010) and mealworm beetles (Krams, Kivleniece, Kuusik, Krama, Freeberg, et al., 2013; Krams, Kivleniece, Kuusik, Krama, Mänd, et al., 2013), and suggested that this was due to individual variation in energy allocation. Studies of Drosophila melanogaster have failed to find significant correlations between MR and life span (e.g. Hulbert et al.,2004; Van Voorhies, Khazaeli, \& Curtsinger, 2003, 2004) while those in Caenorhabditis elegans have shown a negative association between MR and life span (Van Voorhies, 2002; Van Voorhies \& Ward, 1999). The fact that, within species, older individuals often show a lower MR (e.g. Frisard et al., 2007; Khazaeli, Van Voorhies, \& Curtsinger, 2005; Klausen, Toubro, \& Astrup, 1997; Speakman, Van Acker, \& Harper, 2003; Van Voorhies \& Ward, 1999) might reflect resource depletion late in life and has thus been seen as support for the possibility that variation in allocation is important. Alternatively, however, a decrease in age-specific MR might also simply reflect a syndrome of general physiological deterioration with age (Promislow \& Haselkorn, 2002).

A few previous studies have used selection on age-at-reproduction or life span to examine associations between MR and life span, in the fruit fly $D$. melanogaster and in the seed beetle Callosobruchus maculatus. However, these experiments also show contrasting results. For example, Arking, Buck, Wells, and Pretzlaff (1988), Khazaeli et al. (2005) and Mockett, Orr, Rahmandar, Sohal, and Sohal (2001) found that long-lived lines tend to show a higher MR while Berger, Berg, Widegren, Arnqvist, and Maklakov (2014), Djawdan, Rose, and Bradley (1997) and Service (1987) found the precise opposite result. One possible interpretation of the above lack of consistency is that the sign of covariation between MR and life span may be dictated by the nature of genetic variation. In populations dominated by variation in acquisition, we might predict a positive covariation while the opposite prediction would apply to populations dominated by variation in allocation (Houle, 1991; Houle et al., 1994; Maklakov et al., 2015; Tatar, 2001). This hypothesis could be tested by contrasting species that are either income or capital breeders (Stearns, 1992; Stephens, Boyd, McNamara, \& Houston, 2009). Income breeders can obviously show marked variation in energy acquisition while variation in allocation should be more pronounced in capital breeders, with a more invariant total energy budget.

The bean beetle, like many other seed beetles, lay their eggs on dry legume seeds (here, the common bean Phaseolus vulgaris) and the larvae complete their development inside the bean. Emerging adults are capital breeders (Fox, Bush, \& Wallin, 2003; Messina \& Fry, 2003; Messina \& Slade, 1997), which reproduce successfully using 
exclusively resources gathered as juveniles (Leroi, 1981). Because it is so well adapted to using dry seeds, thus relying on metabolic water and resources acquired in the larval stages, the bean beetle has become a significant pest in postharvest crop storages. We assayed metabolic performance (MR and respiratory quotient [RQ]) throughout life in mated and virgin adult males and females from our $E$ and $L$ selection lines. Given that bean beetles are capital breeders, we can make the general prediction that the evolution of a slow POL should result primarily from age-specific shifts in allocation to competing demands that characterises shifts in POLS (Berger et al., 2014). More specifically, we predict that (1) E lines should show a higher MR and (2) rely on a wider range of respiratory substrates for their energy demands, both as a result of evolving to "live-fast-and-die-young." Metabolic rate should then also (3) decrease more rapidly with age in $E$ lines, as a result of resource depletion late in life. We also predict that (4) males should show a higher MR that (5) decreases more rapidly with age for much the same reasons, as sexual selection favours a faster POLS in males (Arnqvist \& Tuda, 2010; Berger et al., 2014; Bonduriansky, Maklakov, Zajitschek, \& Brooks, 2008; Løvlie, Immonen, Gustavsson, Kazancioğlu, \& Arnqvist, 2014). These effects might also (6) be more pronounced in mated individuals, as MR is elevated after mating in seed beetles (Immonen, Liljestrand-Rönn, Watson, Berger, \& Arnqvist, 2016).

\section{2 | MATERIALS AND METHODS}

A base population (B) of $A$. obtectus, from which all selection lines were originally derived, was established in 1983 by mass mating equal numbers of adults from three local subpopulations of $A$. obtectus collected near Belgrade (Tucić et al., 1996). The base population was maintained at a large size ( $N=5,000$ individuals) on $P$. vulgaris seeds on a 40-day schedule in the laboratory for 3 years (27 generations), prior to founding our selection lines. Our replicated selection lines were derived simultaneously from the base population during 1986 and were placed under either of two divergent selection regimes; one in which we selected for reproduction early in life and one in which we selected for late life reproduction. Throughout the course of our longterm selection experiments, reproduction was permitted either only during day 1-2 of adult life (E regime) or in individuals at age 10 days and older ( $\mathrm{L}$ regime). This represents a bi-directional selection design, as peak reproduction in this species normally occurs during day 3-6 of adult life (Parsons \& Credland, 2003).

For a more detailed description of the selection regimes, we refer to Lazarević, Đorđević, Stojković, and Tucić (2013) and Tucić et al. (1996, 1997). Briefly, each $E$ line ( $N=4$ lines) was started with approximately 400 newly emerged adults (sex ratio approximately 1: (1) that were kept together in a rearing jar with an ample supply of seeds for $48 \mathrm{hr}$ to mate and lay eggs at will, after which all adults were removed. To establish each generation in the $L$ selection regime ( $N=4$ lines), approximately 1,000 females and males were kept together in 10 separate vials (i.e. about 100 individuals per vial) without seeds, to depress oviposition. Beetles surviving to day 10 were then introduced into a rearing jar provided with approximately 100 seeds, and any eggs laid prior to day 10 did thus not contribute to the next generation. The selection lines were maintained on $P$. vulgaris seeds in a dark incubator under aphagous conditions at $30^{\circ} \mathrm{C}$. Here, we used beetles from generation 225 of the $E$ and generation 160 of the $L$ lines, which were maintained under common garden conditions without selection for $16 / 14$ generations prior the metabolic assays.

\section{1 | Metabolic assays}

Mating triggers reproduction in this group of beetles, in the form of egg production in females and ejaculate renewal in males (Immonen, Liljestrand-Rönn, et al., 2016; Tatar, Carey, \& Vaupel, 1993), and assaying MR in mated and virgin individuals thus allowed us to compare the effects of selection with and without the cost of reproduction. Virgin beetles of both sexes for the metabolic assays were obtained by individually isolating infested beans in 24-well tissue culture plates and virgin beetles were collected as they emerged. Upon emergence, individuals were randomly assigned to a mating status (virgins or mated) and an age-at-assay ( 2 days, 7 days and, for $L$ line beetles, also 12 days; see below) treatment and were kept in isolation in Eppendorf tubes without beans until the assays described below. For beetles assigned to the mated treatment, we placed five pairs together in a $6 \mathrm{~cm}$ Petri dish at day 2. When a couple had initiated mating, they were transferred to a $3 \mathrm{~cm}$ Petri dish to complete mating. Beetles in the virgin treatment were treated the same way but were separated immediately upon having made contact and so did not mate. This allowed males and females to interact but not to mate, thus isolating the effect of mating from male-female interactions. For our metabolic assays, beetles were then placed in groups of three same sex, same age and same mating treatment triads. Each triad was weighed to the nearest $0.0001 \mathrm{~g}$ (Sartorius ${ }^{\circledR}$ Genius ME 235P-OCE) and was then transferred to a respirometry chamber (a glass cylinder; $17 \mathrm{~mm}$ in diameter and $70 \mathrm{~mm}$ in length).

Age can refer to chronological age or biological age. Since beetles from $L$ lines live much longer than those from $E$ lines, we recorded MR at days 2 and 7 post-emergence in $E$ lines and the base line, and at days 2, 7 and 12 post-emergence in L lines. Because 7 days correspond to the average life span of mated males from $\mathrm{E}$ lines and 12 days to that in L lines (Stojković \& Savković, 2011), day 7 in $\mathrm{E}$ lines and day 12 in L lines were deemed to represent a similar biological age.

Metabolic rate and RQ were measured using a Sable Systems (Las Vegas, NV, USA) respirometry system (Lighton, 2008) (for technical setup and calibration, see Supporting Information). This system pumps air at a very precisely regulated flow rate through a sealed chamber containing animals with a known weight. Downstream gas analysers are then used to measure the amount of $\mathrm{CO}_{2}$ produced and $\mathrm{O}_{2}$ consumed by the beetles, and these measures then provide estimates of metabolic parameters. Briefly, the respirometry system was set up in stop-flow mode (Lighton, 2008), in which each chamber was sealed for a period of $60 \mathrm{~min}$ and then flushed for a period of $2.5 \mathrm{~min}$. Each cycle (through all 24 chambers) lasted for $62.5 \mathrm{~min}$ and each 
measuring session resulted in several readings of $\mathrm{CO}_{2}$ produced and $\mathrm{O}_{2}$ consumed in each individual chamber, of which the first was discarded as a burn-in and the second was used for subsequent analyses. Each respirometry chamber was placed in an activity detector (AD-2, Sable Systems) connected to a data acquisition interface (Quick-DAQ, National Instruments, Coleman Technologies, Newton Square, PA), which uses reflective infra-red light technology to provide a precise and continuous measure of locomotor activity of the subjects in each chamber during the entire session. One of the 24 chambers was left empty and was used as a baseline to control for any drift of the gas analysers during each session (flushed twice in each cycle). Thus, each observation consisted of the amount of $\mathrm{CO}_{2}$ produced and $\mathrm{O}_{2}$ consumed during $60 \mathrm{~min}$ by a triad of beetles under dark conditions and the total amount of activity performed by these three beetles during this time.

\section{3 | RESULTS}

In total, we secured respirometric data from $N=508$ replicates and, overall, the amount of $\mathrm{CO}_{2}$ produced was highly correlated with $\mathrm{O}_{2}$ consumed $(r=.88)$. Our data was unbalanced and our design contained no less than five factorial classifiers and two important continuous covariates (activity and weight). To allow proper estimation of the effects of our factorial variables, while avoiding potential inferential problems due to unbalance, over-parameterisation or inappropriate degrees of freedom, we analysed cell means using repeated-measures ANOVA models (see below) after first having accounted for the effects of our two covariates.

Metabolic rate increases with activity. The activity detectors used in our experimental set-up allowed us to assess and control for this, often neglected and unwanted, source of variance in metabolic data where the aim is to assess resting metabolic rate (RMR). We used the following rationale. Using linear mixed models with line as random effect, activity was indeed a significant predictor of both $\mathrm{CO}_{2}\left(t_{496}=3.85, p<.001\right)$ and $\mathrm{O}_{2}\left(t_{496}=3.49, p<.001\right)$ within lines, explaining a few percent of the variance $\left(R^{2}=.035\right.$ and $R^{2}=.025$, respectively). Importantly, the relationship between $\mathrm{CO}_{2} / \mathrm{O}_{2}$ and activity was linear, as revealed by both graphic inspections and by quadratic mixed models using zero-centered activity data ( $F$-tests of the squared term: $F_{1,495}=0.96, p=.328$ and $F_{1,495}=0.09, p=.758$, respectively), and the relationship between $\mathrm{CO}_{2} / \mathrm{O}_{2}$ and activity did not differ significantly across selection treatments, ages or sexes (two-way interactions $p>.05$ ). To compare activity levels during our metabolic assays across groups, we fitted a repeated-measures ANOVA of mean activity per cell in our design. This showed no significant effects of selection regime $\left(F_{1,6}<0.01, p=.978\right)$, sex $\left(F_{1,6}=0.20, p=.672\right)$, chronological age $\left(F_{1,6}=0.02, p=.899\right)$ or mating status $\left(F_{1,6}=1.74, p=.235\right)$ on activity. We thus ran a common global regression model, and the intercept was then added to the residual $\mathrm{CO}_{2} / \mathrm{O}_{2}$ values and the sum was

TABLE 1 Repeated measures ANOVA of the effects of selection, sex, mating status and age on variation in metabolic rate across selection lines

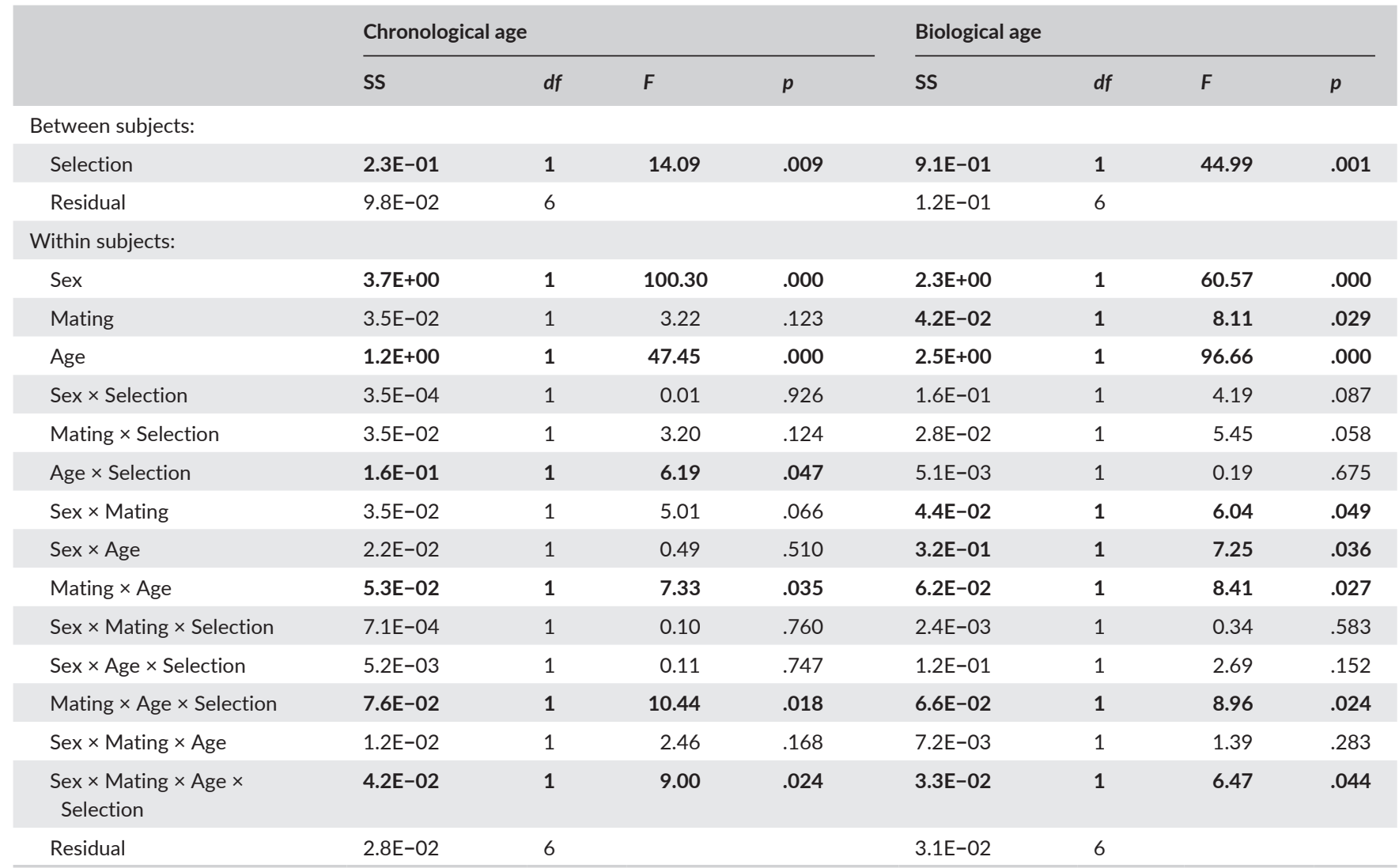

Significant effects (at $p<0.05$ ) are given in bold. 
then retained for all further analysis. These values are thus predicted values for zero activity and, in this sense, represent RMR.

Overall, variance in body weight explained approximately $10 \%$ of the variance in activity adjusted metabolism $\left(R^{2}=.104, F_{1,494}=28.50\right.$, $p<.001$ and $R^{2}=.115, F_{1,494}=25.96, p<.001$ for $\mathrm{CO}_{2}$ and $\mathrm{O}_{2}$, respectively). Moreover, the relationship between $\mathrm{CO}_{2} / \mathrm{O}_{2}$ and weight was linear ( $F$-tests of squared term: $F_{1,493}=0.19, p=.660$ and $F_{1,403}<0.001, p=.989$, respectively) and did not differ significantly across levels of our factorial variables (two-way interactions $p>.05$ ). We estimated the global scaling between weight and metabolism, using nonlinear regression, as activity adjusted $M R=C+$ weight $^{B}$. The scaling for both $\mathrm{CO}_{2}$ ( $\mathrm{C}=0.004$; 95\% CL: $-0.00008,0.008$; and $\mathrm{B}=1.070$; 95\% CL: 0.986, 1.153) and $\mathrm{O}_{2}(\mathrm{C}=0.004$; 95\% CL: $-0.003,0.011$; and $\mathrm{B}=1.026$; $95 \% \mathrm{CL}: 0.899,1.153$ ) was isometric and we thus simply used the ratio between activity adjusted $\mathrm{CO}_{2}\left[\mathrm{O}_{2}\right]$ and weight as our measures of activity and weight adjusted $\mathrm{CO}_{2}\left[\mathrm{O}_{2}\right]$. We used this activity adjusted and weight-specific measure of $\mathrm{CO}_{2}$ production as our measure of $\mathrm{MR}$, as micro-respirometric measures of $\mathrm{CO}_{2}$ are more accurate than those of $\mathrm{O}_{2}$ (see Lighton, 2008). The ratio of activity adjusted and weight-specific measures $\mathrm{RQ}=\mathrm{CO}_{2}$ produced $/ \mathrm{O}_{2}$ consumed (respiratory quotient) was used to test for putative differences

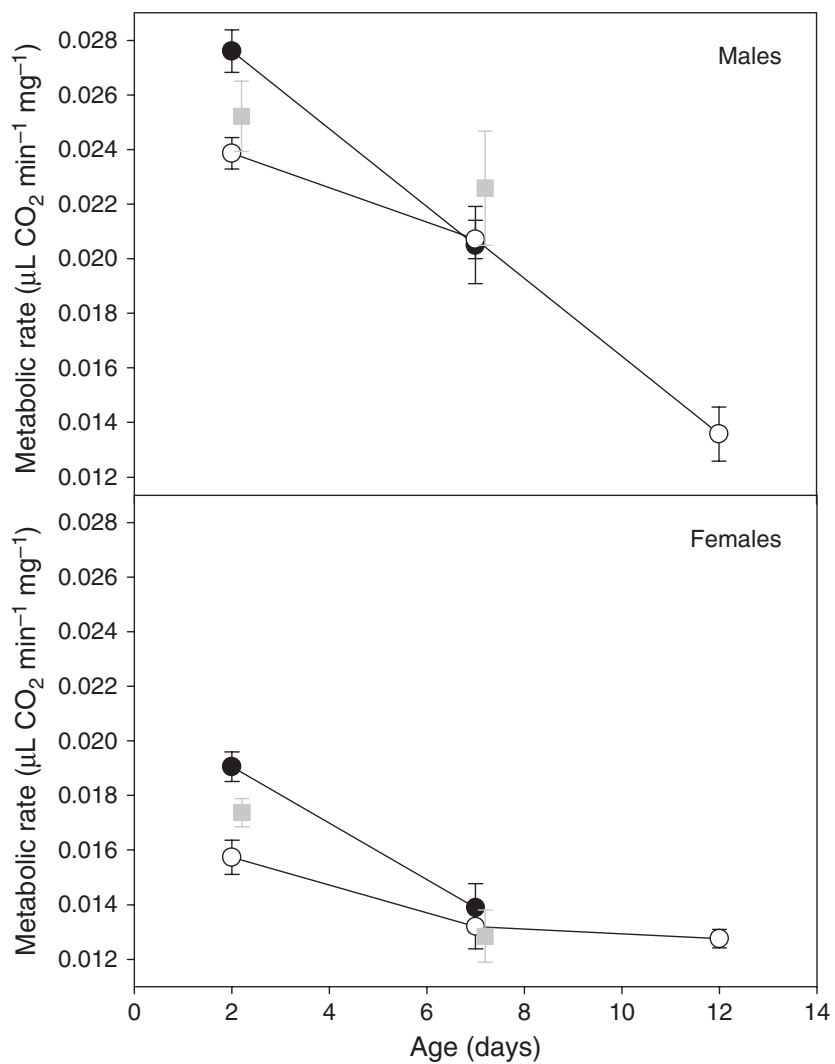

FIGURE 1 Marginal mean \pm SE mass-specific metabolic rate for male (top) and female (bottom) bean beetles from the $E$ (black circles) and $L$ (open circles) selection lines. Metabolic rate was assayed at three different chronological ages in the $L$ lines and at two in the $E$ lines, as day 7 in the $E$ lines and day 12 in the $L$ lines represent a similar biological age. Shown are also the metabolic rate for the baseline population (grey squares), for comparative purposes in the use of metabolic substrates. The respiratory quotient reflects which macronutrients are being used as metabolic fuel, as different energy producing pathways are utilised for fatty acids, carbohydrates and proteins.

We employed repeated-measures ANOVA models to analyse variance in $M R$ and $R Q$, where replicate selection line was treated as the subject, selection as a between-subjects factor and sex, mating status and age as within-subjects factors, based on cell means (average number of observations [triads] per cell: $N=5.79, S D=2.15$; average numbers of beetle individuals per cell $N=17.4$ ). To compare different aspects of age, we ran two analogue models: one using chronological age ( $E$ lines 2 vs. 7 days; L lines 2 vs. 7 days) and one using biological age ( $E$ lines 2 vs. 7 days; L lines 2 vs. 12 days).

Our inferential models showed that beetles deriving from $\mathrm{E}$ lines exhibited a significantly higher MR than did beetles from $L$ lines, in particular when age was modelled as biological age (Table 1). This difference was consistent over sex and mating status, but MR decreased with age more rapidly in $E$ lines compared to L lines (Figure 1), especially so in virgins (Figure 2 ) (Age $\times$ Selection and Mating $\times$ Age $\times$ Selection in Table 1). Overall, these effects seen are primarily the result of the evolution of elevated MR early in life in E lines and depressed MR early in life in $L$ lines, relative to the base population. In term of chronological age, at least, the overall effects of selection at later ages were more marginal (Figures 1 and 2).

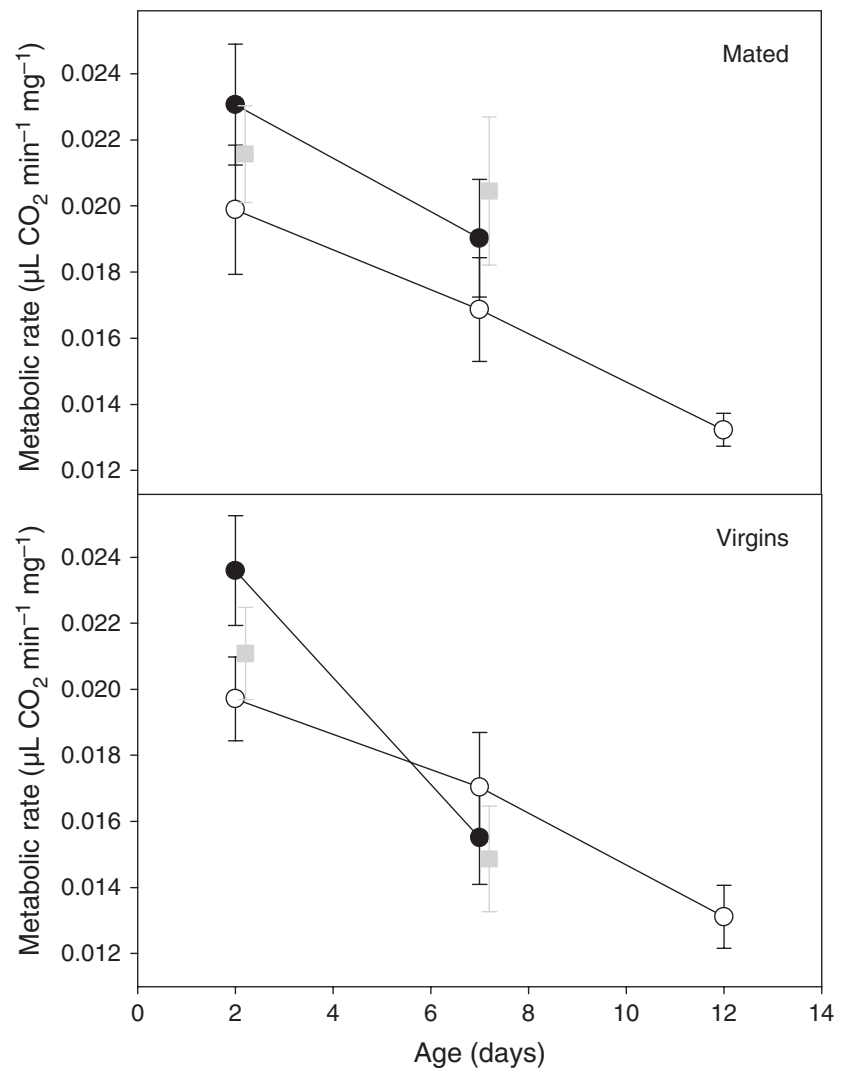

FIGURE 2 Marginal mean $\pm S E$ mass-specific metabolic rate for mated (top) and virgin (bottom) bean beetles from the $E$ (black circles) and $L$ (open circles) selection lines. The baseline population (grey squares) is included for comparative purposes 
TABLE 2 Repeated measures ANOVA of the effects of selection, sex, mating status and age on variation in respiratory quotient across selection lines

\begin{tabular}{|c|c|c|c|c|c|c|c|c|}
\hline & \multicolumn{4}{|c|}{ Chronological age } & \multicolumn{4}{|c|}{ Biological age } \\
\hline \multicolumn{9}{|l|}{ Between subjects: } \\
\hline Selection & 2.7E-03 & 1 & 0.58 & .476 & $2.0 \mathrm{E}-06$ & 1 & 0.00 & .978 \\
\hline Residual & $2.8 \mathrm{E}-02$ & 6 & & & $1.4 \mathrm{E}-02$ & 6 & & \\
\hline Mating & $5.4 \mathrm{E}-03$ & 1 & 3.46 & .112 & $3.2 \mathrm{E}-03$ & 1 & 1.74 & .235 \\
\hline Age & $3.4 \mathrm{E}-03$ & 1 & 1.30 & .298 & $2.5 \mathrm{E}-05$ & 1 & 0.02 & .899 \\
\hline Sex $\times$ Selection & $6.5 \mathrm{E}-04$ & 1 & 0.30 & .605 & $2.7 \mathrm{E}-05$ & 1 & 0.01 & .908 \\
\hline Mating $\times$ Selection & 3.7E-03 & 1 & 2.37 & .175 & $6.0 \mathrm{E}-03$ & 1 & 3.26 & .121 \\
\hline Mating $\times$ Age & $1.6 \mathrm{E}-02$ & 1 & 11.90 & .014 & $1.2 \mathrm{E}-02$ & 1 & 7.86 & .031 \\
\hline Sex $\times$ Mating $\times$ Selection & $9.0 \mathrm{E}-06$ & 1 & 0.01 & .940 & 2.7E-03 & 1 & 0.91 & .377 \\
\hline Sex $\times$ Age $\times$ Selection & $9.2 \mathrm{E}-04$ & 1 & 0.53 & .495 & $1.0 \mathrm{E}-04$ & 1 & 0.03 & .865 \\
\hline Mating $\times$ Age $\times$ Selection & 7.7E-03 & 1 & 5.86 & .052 & $1.1 \mathrm{E}-02$ & 1 & 7.33 & .035 \\
\hline Sex $\times$ Mating $\times$ Age & $3.0 \mathrm{E}-04$ & 1 & 0.35 & .577 & $5.2 \mathrm{E}-03$ & 1 & 2.99 & .134 \\
\hline Sex $\times$ Mating $\times$ Age $\times$ Selection & $9.0 \mathrm{E}-04$ & 1 & 1.06 & .342 & $6.3 \mathrm{E}-04$ & 1 & 0.36 & .571 \\
\hline Residual & $5.1 \mathrm{E}-03$ & 6 & & & $1.0 \mathrm{E}-02$ & 6 & & \\
\hline
\end{tabular}

Significant effects (at $p<0.05$ ) are given in bold.

The strongest main effects, however, were those of sex and age: males showed a markedly elevated MR compared to females and MR generally decreased substantially with age (Table 1). Moreover, when modelling the effects of biological age, MR decreased with age more rapidly in males than it did in females (Sex $\times$ Age in Table 1) (Figure 1). We also note that MR decreased relatively monotonously with age in $\mathrm{L}$ individuals, such that there did not seem to be any marked deceleration of decline in age-specific MR. In contrast, the effects of mating status were more minor (Figure 2). Mated individuals did have an overall slightly higher MR in our model of biological age, as might be expected, but this effect was to large extent due to a very low MR in $E$ line virgins late in life (Mating $\times$ Age and Mating $\times$ Age $\times$ Selection in Table 1).

Our factorial variables had more subtle effects on RQ. The RQ did differ between $E$ lines and $L$ lines, but the effects of selection for age at reproduction on $\mathrm{RQ}$ were embroiled within interactions with age and mating status (Table 2). Across all replicates, $E$ line beetles had a marginally higher overall $R Q$ ( $E$ lines: mean $R Q=0.721, S E=0.010$; L lines: mean $R Q=0.717, S E=0.008$ ) but this difference was more pronounced in mated individuals and young virgins (Figure 3 ). The $R Q$ was exceptionally low in old $E$ line virgins: these beetles showed an RQ lower than 0.7 (Figure 3) and this effect dominated much of the analyses. Focused tests showed that, in virgins, young $E$ line females $\left(F_{1,6}=10.66, p=.017\right)$ and males $\left(F_{1,6}=5.99, p=0.049\right)$ both had a higher mean RQ compared to $L$ lines. The expected values for $R Q$ are $R Q=1$ for pure carbohydrate oxidation, $R Q=0.8$ for proteins and $R Q=0.7$ for pure fatty acid oxidation (Kleiber, 1961). Our results are thus consistent with a metabolism based predominantly on fatty acid oxidation although some degree of alternative respiratory substrates are apparently also used, especially in $E$ lines (Figure 3).

We included metabolic assays of base line beetles in our study, for comparative purposes. Although not included in our inferential models, our results showed that baseline beetles were either intermediate to $\mathrm{E}$ and $\mathrm{L}$ line beetles (especially for MR) or showed metabolic phenotypes that overlapped with these (Figures 1-3).

\section{DISCUSSION}

Overall, our results were consistent with a central role for MR for the divergence in POLS seen in our selection lines, supporting a key position for MR in ecologically relevant life-history trait variation within species. We found that beetles with a fast lifestyle showed a higher MR and a more rapid decline in MR during life. Further, MR was to a large extent sex-specific, consistent with the view that the evolution of POLS results primarily from sex- and age-specific shifts in allocation to competing demands. Markedly depressed MR early in adult life was associated with the evolution documented in previous studies of these beetles, i.e. that of longer juvenile development 


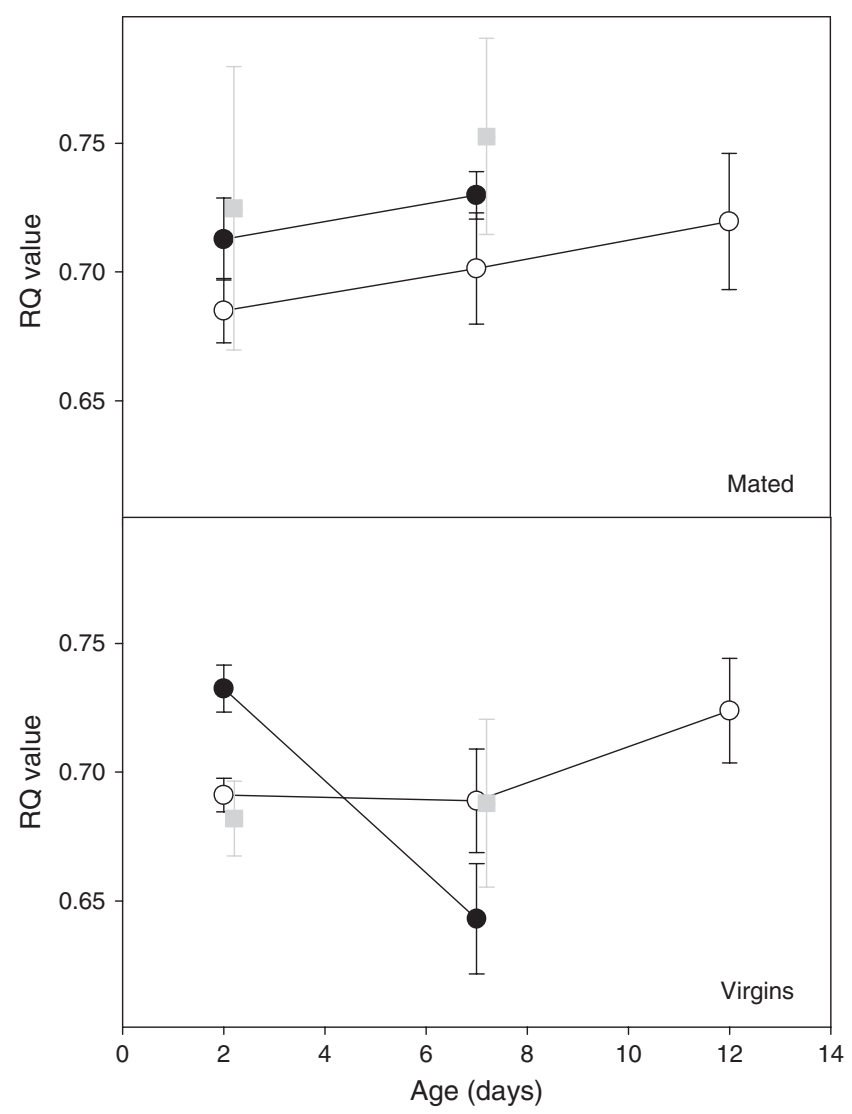

FIGURE 3 Marginal mean \pm SE respiratory quotient for mated (top) and virgin (bottom) bean beetles from the $\mathrm{E}$ (black circles) and $\mathrm{L}$ (open circles) selection lines. The baseline population (grey squares) is included for comparative purposes. A respiratory quotient of 0.7 is expected for pure lipid oxidation

time, larger body size, depressed reproductive effort early in life, prolonged life span and a decreased rate of senescence (see Đorđević et al., 2015; Stojković \& Savković, 2011; Tucić et al., 1996, 1997, 2004). Overall, MR was $18 \%$ higher early in life in $E$ lines compared to $L$ lines. Metabolic rate also decreased more rapidly with chronological age in $E$ lines, presumably as a result of resource depletion late in life. In terms of the evolution of life span, the results of our study confirms the suggestion of Berger et al. (2014) that aphagous seed beetles represent a system that matches the key assumptions made under the ROL hypothesis fairly well (Pearl, 1928; Rubner, 1908). In these insects, both phenotypic (Tatar et al., 1993) and evolutionary (Tucić et al., 1996, 2004) elevation of early reproductive effort are associated with decreased life span. Being capital breeders, this is apparently the result of resource depletion as individuals age (Lazarević, Tucić, Šešlija Jovanović, Večeřa, \& Kodrík, 2012) leading to advanced onset of senescence as well as an accelerated rate of senescence (Stojković \& Savković, 2011; Tatar et al., 1993). In line with this interpretation, Lazarević et al. (2012) showed that the consumption of metabolite resources is retarded during adult ageing in bean beetles from $L$ lines. Here, we confirm that bean beetles selected for early reproduction have indeed evolved a markedly higher MR. Below, we discuss some more specific insights gained by our experiments.

\section{1 | More than ROL?}

Under a strict definition of the ROL hypothesis, the total mass-specific energy expenditure per life span should be fixed (Pearl, 1928; Speakman, 2005). This does not quite seem to be true in our selection lines. Using data on mean longevity of virgin beetles from Stojković and Savković (2011), the product of mass-specific MR at 2 days observed here and mean life span is some $66 \%$ higher in $L$ females than in $E$ females $(0.30$ vs. 0.18 ) and some $22 \%$ higher in $L$ males than in E males (0.34 vs. 0.28). In other words, although MR is indeed higher in $E$ line beetles than in $L$ line beetles, it does not seem high enough to account for the large difference seen in mean life span (18.2 vs. 9.4 and 15.3 vs. 10.2 days). Phrased differently, $\mathrm{L}$ beetles seem to live longer than expected under the ROL hypothesis. We note that we assayed whole-animal metabolic rate and although $L$ beetles are larger than $E$ beetles, the size difference is thus not large enough to account for their longer life span. Differential investment in reproduction is also not likely a major contributor since this data concerns virgins. Yet, our selection lines might show differential costs of germline maintenance even in the absence of reproduction (Maklakov \& Immler, 2016) but this is unlikely given that lifetime fecundity is of similar magnitude in $\mathrm{E}$ and $\mathrm{L}$ lines (Đorđević et al., 2015; Tucić et al., 2004). Several factors could, however, contribute to this apparent quantitative discrepancy. For example, our estimates of MR may be imperfect measures of energetic expenditure or, alternatively, the shared dependency between MR and life span on body size might be more complicated than a simple scaling assumes (Speakman, 2005). Moreover, allocation of resources to other competing demands likely contributes to the differences seen in life span and ageing. Most importantly, it has been shown that $L$ beetles exhibit higher expression of antioxidant defence compounds (Šešlija, Blagojević, Spasić, \& Tucić, 1999) and, consequently, are more resistant to oxidative stress (Lazarević et al., 2013). This suggests that differential ROS production and/or defence against ROS may in part be responsible for divergent evolution of life span and ageing seen in our selection lines, illustrating the more general point that the classic ROL and the "free radical" hypotheses for the evolution of ageing are not mutually exclusive.

\subsection{Sexual dimorphism in metabolic rate}

It has been suggested that male seed beetles follow a fast POLS, largely as a result of intense reproductive competition for mating opportunities early in life which selects for protandry and investment in costly mate searching and ejaculate production (Arnqvist \& Tuda, 2010; Bonduriansky et al., 2008; Fox, Stillwell, \& Moya-Larano, 2007; Maklakov \& Lummaa, 2013). In most seed beetles species, the pattern of sexual dimorphism is consistent with this: males have a more rapid juvenile development (Arnqvist \& Tuda, 2010; Dowling, Abiega, \& Arnqvist, 2007; Šešlija \& Tucić, 2003), a smaller body size (Fox et al., 2007; Stojković \& Savković, 2011), a higher MR (Berger et al., 2014), are more active (Berger et al., 2014; Løvlie et al., 2014) and have a shorter life span (Berger et al., 2014; Fox, Dublin, \& Pollitt, 2003; Leroi, 1981; Stojković \& Savković, 2011) compared to females. Reproductive competition among males early in life is thought to be strong in both $E$ and 
L lines (Šešlija, Lazarević, Janković, \& Tucić, 2009; Stojković et al., 2010; Stojković, Šešlija Jovanović, Perovanović, \& Tucić, 2011) and our results are consistent with the above scenario: male and female bean beetles differed markedly in MR. In fact, MR was 50\% higher in males compared to females (at days 2 and 7) and the effect of sex was the strongest seen in our analyses. Further, MR also decreased more rapidly with biological age in males, especially in $L$ lines. These differences in sex- and agespecific MR are well matched by the sex- and age-specific availability of primary metabolic substrates (i.e. lipids), which is higher in males than in females but decreases with age more rapidly in $L$ line males than in L line females (Lazarević et al., 2012). We note that the costs of mating and mate searching to males are substantial in this group of insects (Berger et al., 2014; Immonen, Liljestrand-Rönn, et al., 2016; Paukku \& Kotiaho, 2005; Salehialavi, Fritzsche, \& Arnqvist, 2011) and male investment in costly ejaculates decreases with age (Fox, Hickman, Raleigh, \& Mousseau, 1995; Immonen, Collet, Goenaga, \& Arnqvist, 2016). In conclusion, bean beetle males indeed seem adapted to "live-fast-dieyoung": selection for a relatively high MR early in life have apparently led to a depletion of allocable resources and rapid ageing.

\subsection{The use of respiratory substrates}

Our results show that the metabolism of beetles from our selection lines is based almost exclusively on lipids, as is typical in seed beetles (Immonen, Liljestrand-Rönn, Watson, Berger, \& Arnqvist, 2016; Wightman, 1978), although beetles from the $E$ lines apparently also used other respiratory substrates (proteins and/or carbohydrates). Alternative substrates show several differences in, for example, energy content, regulation of catabolic pathways, ATP synthesis rate and efficiency, metabolic water generation, mitochondrial oxidative phosphorylation and reactive oxygen production (Harrison, Woods, \& Roberts, 2012; Willmer, Stone, \& Johnston, 2009). We suggest that L lines may have evolved to rely more exclusively on lipids either (1) to avoid longterm dehydration, as more metabolic water is released under fatty acid oxidation, or (2) to maximise long-lasting energy reserves, as fatty acids are a more energy-dense substrate. These two possibilities are not mutually exclusive, and we note that both have some support from the fact that $L$ lines beetles are larger (Tucić et al., 1996) and have a higher weight-specific lipid content but a lower weight-specific soluble protein content (Lazarević et al., 2012). In a reflection of the second possibility, E lines should rely on all available respiratory substrates to maximise energy output early in life. Lazarević et al. (2012) thus suggested that selection for higher protein content in $\mathrm{E}$ lines at the expense of lipid storage, to allow protein investment in reproduction early in life, may render $\mathrm{E}$ lines beetles to also utilise proteins as a respiratory substrate. Our results provide some support for this possibility, in the form of a higher RQ in E lines early in life. Otherwise, changes at the concentration of available metabolites (Lazarević et al., 2012) and in the respiratory quotient in our selection lines were well matched. For example, the concentration of soluble proteins increases and that of lipids decreases with age, and RQ tended to increase overall with age (Figure 3).

Our data also suggests that the metabolic machinery was altered, and possibly challenged, towards the end life. This was most apparent in virgin $E$ line beetles, which showed depressed $M R$ and an exceptionally low RQ late in life. The RQ of these beetles was even lower than the theoretical minimum of 0.7 predicted under pure fatty acid oxidation (Kleiber, 1961). However, RQs lower than 0.7 have often been observed in insects (e.g., Blossman-Myer \& Burggren, 2010; Damcevski, Annis, \& Waterford, 1998; DeVries, Kells, \& Appel, 2015; Rouland, Brauman, Labat, \& Lepage, 1993; Vogt \& Appel, 1999) and are predicted to occur under starvation when, for example, a net synthesis of ketone bodies from fat may occur (Schutz \& Ravussin, 1980). Alternatively, the low RQ may reflect a need to avoid dehydration by generating metabolic water late in life through desaturation of fatty acids, which consumes oxygen to form water but produces no carbon dioxide (Lopez-Martinez et al., 2009; Owen, Smalley, D’Alessio, Mozzoli, \& Dawson, 1998). However, the ingestion of water does not noticeably prolong life span in bean beetles (Leroi, 1981), suggesting that dehydration is not a major issue, and it is not clear why such an effect would be most apparent in virgin $E$ line beetles. An alternative explanation is that the cost of mating and reproduction, estimated as the difference between virgin and mated individuals (Immonen, Liljestrand-Rönn, et al., 2016), was most apparent in $\mathrm{E}$ line beetles when mated late in life, possibly because these beetles are not well adapted to mating late in life.

\subsection{Mitochondrial ETC activity and metabolic rate}

It is often of interest to predict ecologically relevant functional traits from underlying physiological rates. A basic expectation in ecological physiology is that MR should reflect activities of enzymes involved in metabolic networks. One might, for example, expect that the rate at which major metabolic enzymes process their substrates should be positively related to the MR of the organism that hosts these enzyme complexes (Ballard \& Pichaud, 2014). Yet, recent in-vitro assays of the activity of the multi-subunit complex of the electron transport chain (ETC) involved in oxidative phosphorylation (OXPHOS) in mitochondria, in 1-day-old virgin adults from our selection lines, have shown that ETC activity per protein unit is actually (1) higher in L lines than E lines and (2) higher in females than in males (see Đorđević et al., 2017). We note that these rates are the precise opposite to the differences in whole organism MR documented here. This may seem puzzling or even contradictory at first. However, there are good reasons for why such a relationship could be obscured or even reversed. The respiratory activity of the ETC chain is regulated by both anterograde and retrograde signalling pathways and depends in part on the assembly of the subunits of respiratory complexes. The regulation of mitochondrial function and biogenesis is thus complex and only partly understood and there are several mechanisms by which a particular mitochondrial phenotype (i.e. ETC activity) may be disentangled from or even reversely related to the whole organism phenotype (i.e. MR) (Garesse \& Vallejo, 2001; Kelly \& Scarpulla, 2004). More generally, many studies have suggested that the in-vitro activity of individual metabolic enzymes may often poorly reflect in-vivo flux rate of entire metabolic pathways (e.g. Flowers et al., 2007; Marden, 2013; Montooth, Marden, \& Clark, 2003). For example, Montooth et al. (2003) found that invitro activity of phosphoglucoisomerase (PGI) correlates negatively 
with MR in Drosophila. Similarly, Jumbo-Lucioni et al. (2010), in a genome-wide screen of inbred Drosophila lines, found 61 genes associated with phenotypic variation in MR of which only one is involved in OXPHOS. Thus, although the evolution of MR in our bean beetle selection lines has clearly involved changes in mitochondrial enzymatic activity (Arnqvist et al., 2010; Đorđević et al., 2017; Šešlija Jovanović, Đorđević, Savković, \& Lazarević, 2014; Stojković et al., 2017), the precise manner in which these changes have contributed to net metabolic flux rate is currently unclear. Thus, predicting variation in ecologically relevant functional traits and vital rates from underlying physiological rates is not always straightforward (Marden, 2013).

In conclusion, although our results illustrate the fact that whole organism MR is a complex trait, they also show that MR plays a central role in the divergence of "pace-of-life" seen in bean beetles. In this sense, our findings provide novel support for view that MR lies at the root of intraspecific variation in ecologically relevant life-history traits.

\section{ACKNOWLEDGEMENTS}

We extend our deepest gratitude to the late Nikola Tucić, who made this study possible. We thank A. Maklakov for comments and constructive discussions. This contribution was supported by the European Research Council (GENCON AdG-294333), the Swedish Research Council (621-2014-4523) and the Serbian Ministry of Education, Science and Technological Development (grant No. 173007). The authors declare that they have no conflicting interests.

\section{AUTHORS' CONTRIBUTIONS}

G.A., B.S., J.L.R. and E.I. conceived the ideas and designed methodology; B.S. maintained the selection lines; J.L.R. and E.I. collected the data; G.A., J.L.R. and E.I. analysed the data; G.A. led the writing of the manuscript. All authors contributed critically to the drafts and gave final approval for publication.

\section{DATA ACCESSIBILITY}

Data reported in this paper have been published in Mendeley Data and are available at https://doi.org/10.17632/dc7jxmvctm.1 (Arnqvist, Stojković, Ronn, \& Immonen, 2017).

\section{REFERENCES}

Arking, R., Buck, S., Wells, R. A., \& Pretzlaff, R. (1988). Metabolic rates in genetically based long lived strains of Drosophila. Experimental Gerontology, 23, 59-76.

Arnqvist, G., Dowling, D. K., Eady, P., Gay, L., Tregenza, T., Tuda, M., \& Hosken, D. J. (2010). The genetic architecture of metabolic rate: Environment specific epistasis between mitochondrial and nuclear genes in an insect. Evolution, 64, 3354-3363.

Arnqvist, G., Stojković, B., Ronn, J.L., \& Immonen, E. (2017). Data from: The pace-of-life: A sex-specific link between metabolic rate 3 and life history in bean beetles. Mendeley Data v.1, https://doi.org/10.17632/ dc7jxmvctm.1

Arnqvist, G., \& Tuda, M. (2010). Sexual conflict and the gender load: Correlated evolution between population fitness and sexual dimorphism in seed beetles. Proceedings of the Royal Society of London B, 277, 1345-1352.

Artacho, P., \& Nespolo, R. F. (2009). Natural selection reduces energy metabolism in the garden snail, Helix aspersa (Cornu aspersum). Evolution, 63, 1044-1050.

Ballard, J. W. O., \& Pichaud, N. (2014). Mitochondrial DNA: More than an evolutionary bystander. Functional Ecology, 28, 218-231.

Bassar, R. D., Marshall, M. C., López-Sepulcre, A., Zandonà, E., Auer, S. K., Travis, J., ... Reznick, D. N. (2010). Local adaptation in Trinidadian guppies alters ecosystem processes. Proceedings of the National Academy of Sciences, 107, 3616-3621.

Berger, D., Berg, E. C., Widegren, W., Arnqvist, G., \& Maklakov, A. A. (2014). Multivariate intralocus sexual conflict in seed beetles. Evolution, 68, 3457-3469.

Blossman-Myer, B. L., \& Burggren, W. W. (2010). Metabolic allometry during development and metamorphosis of the silkworm Bombyx mori: Analyses, patterns, and mechanisms. Physiological and Biochemical Zoology, 83, 215-231.

Bonduriansky, R., Maklakov, A., Zajitschek, F., \& Brooks, R. (2008). Sexual selection, sexual conflict and the evolution of ageing and life span. Functional Ecology, 22, 443-453.

Boratyński, Z., Koskela, E., Mappes, T., \& Oksanen, T. A. (2010). Sex-specific selection on energy metabolism-selection coefficients for winter survival. Journal of Evolutionary Biology, 23, 1969-1978.

Boratyński, Z., \& Koteja, P. (2010). Sexual and natural selection on body mass and metabolic rates in free-living bank voles. Functional Ecology, 24, 1252-1261.

Brand, M. D. (2000). Uncoupling to survive? The role of mitochondrial inefficiency in ageing. Experimental Gerontology, 35, 811-820.

Brown, J. H., Gillooly, J. F., Allen, A. P., Savage, V. M., \& West, G. B. (2004). Toward a metabolic theory of ecology. Ecology, 85, 1771-1789.

Burton, T., Killen, S. S., Armstrong, J. D., \& Metcalfe, N. B. (2011). What causes intraspecific variation in resting metabolic rate and what are its ecological consequences? Proceedings of the Royal Society of London B, 278, 3465-3473.

Careau, V., Bininda-Emonds, O. R. P., Thomas, D. W., Réale, D., \& Humphries, M. M. (2009). Exploration strategies map along fast-slow metabolic and life-history continua in muroid rodents. Functional Ecology, 23, 150-156.

Damcevski, K., Annis, P., \& Waterford, C. (1998). Effect of grain on apparent respiration of adult stored-product Coleoptera in an air-tight system: Implications for fumigant testing. Journal of Stored Products Research, 34, 331-339.

DeVries, Z. C., Kells, S. A., \& Appel, A. G. (2015). Effects of starvation and molting on the metabolic rate of the bed bug (Cimex lectularius L.). Physiological and Biochemical Zoology, 88, 53-65.

Djawdan, M., Rose, M. R., \& Bradley, T. J. (1997). Does selection for stress resistance lower metabolic rate? Ecology, 78, 828-837.

Đorđević, M., Savković, U., Lazarević, J., Tucić, N., \& Stojković, B. (2015). Intergenomic interactions in hybrids between short-lived and longlived lines of a seed beetle: Analyses of life history traits. Evolutionary Biology, 42, 461-472.

Đorđević, M., Stojković, B., Savković, U., Immonen, E., Tucić, N., Lazarević, J., \& Arnqvist, G. (2017). Sex-specific mitonuclear epistasis and the evolution of mitochondrial bioenergetics, ageing and life history in seed beetles. Evolution, 71, 274-288.

Dowling, D. K., Abiega, K. C., \& Arnqvist, G. (2007). Temperature-specific outcomes of cytoplasmic-nuclear interactions on egg-to-adult development time in seed beetles. Evolution, 61, 194-201.

Flowers, J. M., Sezgin, E., Kumagai, S., Duvernell, D. D., Matzkin, L. M., Schmidt, P. S., \& Eanes, W. F. (2007). Adaptive evolution of metabolic pathways in Drosophila. Molecular Biology and Evolution, 24, 1347-1354.

Fox, C. W., Bush, M. L., \& Wallin, W. G. (2003). Maternal age affects offspring lifespan of the seed beetle, Callosobruchus maculatus. Functional Ecology, 17, 811-820. 
Fox, C. W., Dublin, L., \& Pollitt, S. J. (2003). Gender differences in lifespan and mortality rates in two seed beetle species. Functional Ecology, 17, 619-626.

Fox, C. W., Hickman, D. L., Raleigh, E. L., \& Mousseau, T. A. (1995). Paternal investment in a seed beetle (Coleoptera: Bruchidae): Influence of male size, age, and mating history. Annals of the Entomological Society of America, 88, 100-103.

Fox, C. W., Stillwell, R. C., \& Moya-Larano, J. (2007). Variation in selection, phenotypic plasticity, and the ecology of sexual size dimorphism in two seed-feeding beetles. In D. J. Fairbairn, W. U. Blanckenhorn, \& T. Székely (Eds.), Sex, size, and gender roles: Evolutionary studies of sexual size dimorphism (pp. 88-96). Oxford, UK: Oxford University Press.

Frisard, M. I., Broussard, A., Davies, S. S., Roberts, L. J., Rood, J., De Jonge, L., ... Ravussin, E. (2007). Aging, resting metabolic rate, and oxidative damage: Results from the Louisiana Healthy Aging Study. The Journals of Gerontology Series A: Biological Sciences and Medical Sciences, 62, 752-759.

Galliard, J. F., Paquet, M., Cisel, M., \& Montes-Poloni, L. (2013). Personality and the pace-of-life syndrome: Variation and selection on exploration, metabolism and locomotor performances. Functional Ecology, 27, 136-144.

Garesse, R., \& Vallejo, C. G. (2001). Animal mitochondrial biogenesis and function: A regulatory cross-talk between two genomes. Gene, 263, 1-16.

Harman, D. (1956). Aging: A theory based on free radical and radiation chemistry. Journal of Gerontology, 11, 298-300.

Harrison, J. F., Woods, H. A., \& Roberts, S. P. (2012). Ecological and environmental physiology of insects. Oxford, UK: Oxford University Press.

Holzerová, E., \& Prokisch, H. (2015). Mitochondria: Much ado about nothing? How dangerous is reactive oxygen species production? The International Journal of Biochemistry \& Cell Biology, 63, 16-20.

Houle, D. (1991). Genetic covariance of fitness correlates: What genetic correlations are made of and why it matters. Evolution, 45, 630-648.

Houle, D., Hughes, K. A., Hoffmaster, D. K., Ihara, J., Assimacopoulos, S., \& Charlesworth, B. (1994). The effects of spontaneous mutation on quantitative traits. I. Variances and covariances of life history traits. Genetics, 138, 773-785.

Hulbert, A. J., Clancy, D. J., Mair, W., Braeckman, B. P., Gems, D., \& Partridge, L. (2004). Metabolic rate is not reduced by dietary-restriction or by lowered insulin/IGF-1 signalling and is not correlated with individual lifespan in Drosophila melanogaster. Experimental Gerontology, 39, 1137-1143

Immonen, E., Collet, M., Goenaga, J., \& Arnqvist, G. (2016). Direct and indirect genetic effects of mitonuclear epistasis on sex-specific reproductive ageing. Heredity, 116, 338-347.

Immonen, E., Liljestrand-Rönn, J., Watson, C., Berger, D., \& Arnqvist, G. (2016). Complex mitonuclear interactions and metabolic costs of mating in male seed beetles. Journal of Evolutionary Biology, 29, 360-370.

Jackson, D. M., Trayhurn, P., \& Speakman, J. R. (2001). Associations between energetics and over-winter survival in the short-tailed field vole Microtus agrestis. Journal of Animal Ecology, 70, 633-640.

Jumbo-Lucioni, P., Ayroles, J. F., Chambers, M. M., Jordan, K. W., Leips, J., Mackay, T. F., \& De Luca, M. (2010). Systems genetics analysis of body weight and energy metabolism traits in Drosophila melanogaster. BMC Genomics, 11, 1

Kelly, D. P., \& Scarpulla, R. C. (2004). Transcriptional regulatory circuits controlling mitochondrial biogenesis and function. Genes \& Development, 18, 357-368.

Khazaeli, A. A., Van Voorhies, W., \& Curtsinger, J. W. (2005). Longevity and metabolism in Drosophila melanogaster. Genetics, 169, 231-242.

Klausen, B., Toubro, S., \& Astrup, A. (1997). Age and sex effects on energy expenditure. The American Journal of Clinical Nutrition, 65, 895-907.

Kleiber, M. (1961). The fire of life: An introduction to animal energetics. New York, NY: John Wiley \& Sons.

Krams, I., Kivleniece, I., Kuusik, A., Krama, T., Freeberg, T. M., Mänd, R., ... Mänd, M. (2013). Predation selects for low resting metabolic rate and consistent individual differences in anti-predator behavior in a beetle. Acta Ethologica, 16, 163-172.
Krams, I., Kivleniece, I., Kuusik, A., Krama, T., Mänd, R., Rantala, M. J., ... Mänd, M. (2013). Predation promotes survival of beetles with lower resting metabolic rates. Entomologia Experimentalis et Applicata, 148, 94-103.

Lane, N. (2011). Mitonuclear match: Optimizing fitness and fertility over generations drives ageing within generations. BioEssays, 33, 860-869.

Lazarević, J., Đorđević, M., Stojković, B., \& Tucić, N. (2013). Resistance to prooxidant agent paraquat in the short-and long-lived lines of the seed beetle (Acanthoscelides obtectus). Biogerontology, 14, 141-152.

Lazarević, J., Tucić, N., Šešlija Jovanović, D., Večeřa, J., \& Kodrík, D. (2012). The effects of selection for early and late reproduction on metabolite pools in Acanthoscelides obtectus Say. Insect Science, 19, 303-314.

Leroi, B. (1981). Feeding, longevity and reproduction of adults of Acanthoscelides obtectus Say in laboratory conditions. In V. Labeyrie (Ed.), The ecology of Bruchids attacking legumes (Pulses) (pp. 101-111). Dordrecht, the Netherlands: Springer.

Lighton, J. R. (2008). Measuring metabolic rates: A manual for scientists. Oxford, UK: Oxford University Press.

Lopez-Martinez, G., Benoit, J. B., Rinehart, J. P., Elnitsky, M. A., Lee, R. E. Jr, \& Denlinger, D. L. (2009). Dehydration, rehydration, and overhydration alter patterns of gene expression in the Antarctic midge, Belgica antarctica. Journal of Comparative Physiology B, 179, 481-491.

Løvlie, H., Immonen, E., Gustavsson, E., Kazancioğlu, E., \& Arnqvist, G. (2014). The influence of mitonuclear genetic variation on personality in seed beetles. Proceedings of the Royal Society of London B, 281. https:// doi.org/10.1098/rspb.2014.1039

Maklakov, A. A., \& Immler, S. (2016). The expensive germline and the evolution of ageing. Current Biology, 26, R577-R586.

Maklakov, A. A., \& Lummaa, V. (2013). Evolution of sex differences in lifespan and aging: Causes and constraints. BioEssays, 35, 717-724.

Maklakov, A. A., Rowe, L., \& Friberg, U. (2015). Why organisms age: Evolution of senescence under positive pleiotropy? BioEssays, 37, 802-807.

Marden, J. H. (2013). Nature's inordinate fondness for metabolic enzymes: Why metabolic enzyme loci are so frequently targets of selection. Molecular Ecology, 22, 5743-5764.

Martin, L. B., Hasselquist, D., \& Wikelski, M. (2006). Investment in immune defense is linked to pace of life in house sparrows. Oecologia, 147, 565-575.

McGill, B. J., Enquist, B. J., Weiher, E., \& Westoby, M. (2006). Rebuilding community ecology from functional traits. Trends in Ecology \& Evolution, 21, 178-185.

Messina, F. J., \& Fry, J. D. (2003). Environment-dependent reversal of a life history trade-off in the seed beetle Callosobruchus maculatus. Journal of Evolutionary Biology, 16, 501-509.

Messina, F. J., \& Slade, A. F. (1997). Inheritance of host-plant choice in the seed beetle Callosobruchus maculatus (Coleoptera: Bruchidae). Annals of the Entomological Society of America, 90, 848-855.

Mockett, R. J., Orr, W. C., Rahmandar, J. J., Sohal, B. H., \& Sohal, R. S. (2001). Antioxidant status and stress resistance in long-and short-lived lines of Drosophila melanogaster. Experimental Gerontology, 36, 441-463.

Montooth, K. L., Marden, J. H., \& Clark, A. G. (2003). Mapping determinants of variation in energy metabolism, respiration and flight in Drosophila. Genetics, 165, 623-635.

Nespolo, R. F., \& Franco, M. (2007). Whole-animal metabolic rate is a repeatable trait: A meta-analysis. Journal of Experimental Biology, 210, 2000-2005.

Owen, O. E., Smalley, K. J., D'Alessio, D. A., Mozzoli, M. A., \& Dawson, E. K. (1998). Protein, fat, and carbohydrate requirements during starvation: Anaplerosis and cataplerosis. American Journal of Clinical Nutrition, 68, 12-34.

Parsons, D. M., \& Credland, P. F. (2003). Determinants of oviposition in Acanthoscelides obtectus: A nonconformist bruchid. Physiological Entomology, 28, 221-231.

Paukku, S., \& Kotiaho, J. S. (2005). Cost of reproduction in Callosobruchus maculatus: Effects of mating on male longevity and the effect of male mating status on female longevity. Journal of Insect Physiology, 51, 1220-1226. 
Pearl, R. (1928). The rate of living. London, UK: University of London Press.

Promislow, D. E., \& Haselkorn, T. S. (2002). Age-specific metabolic rates and mortality rates in the genus Drosophila. Aging Cell, 1, 66-74.

Réale, D., Garant, D., Humphries, M. M., Bergeron, P., Careau, V., \& Montiglio, P. O. (2010). Personality and the emergence of the pace-oflife syndrome concept at the population level. Philosophical Transactions of the Royal Society of London B, 365, 4051-4063.

Reznick, D. N. (2013). A critical look at reciprocity in ecology and evolution: Introduction to the symposium. American Naturalist, 181, S1-S8.

Reznick, D. N., Bryant, M. J., Roff, D., Ghalambor, C. K., \& Ghalambor, D. E. (2004). Effect of extrinsic mortality on the evolution of senescence in guppies. Nature, 431, 1095-1099.

Ricklefs, R. E., \& Wikelski, M. (2002). The physiology/life-history nexus. Trends in Ecology \& Evolution, 17, 462-468.

Rouland, C., Brauman, A., Labat, M., \& Lepage, M. (1993). Nutritional factors affecting methane emission from termites. Chemosphere, 26 , 617-622.

Rubner, M. (1908). Das Problem der Lebensdauer und seine Beziehungen zu Wachstum und Ernährung. München, Germany: Oldenbourg.

Salehialavi, Y., Fritzsche, K., \& Arnqvist, G. (2011). The cost of mating and mutual mate choice in 2 role-reversed honey locust beetles. Behavioral Ecology, 22, 1104-1113.

Schoener, T. W. (2011). The newest synthesis: Understanding the interplay of evolutionary and ecological dynamics. Science, 331, 426-429.

Schutz, Y., \& Ravussin, E. (1980). Respiratory quotients lower than 0.70 in ketogenic diets. American Journal of Clinical Nutrition, 33, 1317-1319.

Selman, C., Blount, J. D., Nussey, D. H., \& Speakman, J. R. (2012). Oxidative damage, ageing, and life-history evolution: Where now? Trends in Ecology \& Evolution, 27, 570-577.

Service, P. M. (1987). Physiological mechanisms of increased stress resistance in Drosophila melanogaster selected for postponed senescence. Physiological Zoology, 60, 321-326.

Šešlija, D., Blagojević, D., Spasić, M., \& Tucić, N. (1999). Activity of superoxide dismutase and catalase in the bean weevil (Acanthoscelides obtectus) selected for postponed senescence. Experimental Gerontology, 34, 185-195.

Šešlija Jovanović, D., Đorđević, M., Savković, U., \& Lazarević, J. (2014). The effect of mitochondrial complex I inhibitor on longevity of short-lived and long-lived seed beetles and its mitonuclear hybrids. Biogerontology, 15, 487-501.

Šešlija, D., Lazarević, J., Janković, B., \& Tucić, N. (2009). Mating behavior in the seed beetle Acanthoscelides obtectus selected for early and late reproduction. Behavioral Ecology, 20, 547-552.

Šešlija, D., \& Tucić, N. (2003). Selection for developmental time in bean weevil (Acanthoscelides obtectus): Correlated responses for other life history traits and genetic architecture of line differentiation. Entomologia Experimentalis et Applicata, 106, 19-35.

Speakman, J. R. (2005). Body size, energy metabolism and lifespan. Journal of Experimental Biology, 208, 1717-1730.

Speakman, J. R., Talbot, D. A., Selman, C., Snart, S., McLaren, J. S., Redman, P., ... Brand, M. D. (2004). Uncoupled and surviving: Individual mice with high metabolism have greater mitochondrial uncoupling and live longer. Aging Cell, 3, 87-95.

Speakman, J. R., Van Acker, A., \& Harper, E. J. (2003). Age-related changes in the metabolism and body composition of three dog breeds and their relationship to life expectancy. Aging Cell, 2, 265-275.

Stearns, S. C. (1992). The evolution of life histories. Oxford, UK: Oxford University Press.

Stephens, P. A., Boyd, I. L., McNamara, J. M., \& Houston, A. I. (2009). Capital breeding and income breeding: Their meaning, measurement, and worth. Ecology, 90, 2057-2067.

Stojković, B., \& Savković, U. (2011). Gender differences in longevity in early and late reproduced lines of the seed beetle. Archives of Biological Sciences, 63, 129-136.
Stojković, B., Sayadi, A., Đorđević, M., Jović, J., Savković, U., \& Arnqvist, G. (2017). Divergent evolution of life span associated with mitochondrial DNA evolution. Evolution, 71, 160-166.

Stojković, B., Šešlija Jovanović, D., Perovanović, J., \& Tucić, N. (2011). Sexual activity and reproductive isolation between age-specific selected populations of seed beetle. Ethology, 117, 812-821.

Stojković, B., Šešlija Jovanović, D., Tucić, B., \& Tucić, N. (2010). Homosexual behaviour and its longevity cost in females and males of the seed beetle Acanthoscelides obtectus. Physiological Entomology, 35, 308-316.

Tatar, M. (2001). Senescence. In C. W. Fox, D. A. Roff, \& D. J. Fairbairn (Eds.), Evolutionary ecology: Concepts and case studies (pp. 128-141). Oxford, NY: Oxford University Press.

Tatar, M., Carey, J. R., \& Vaupel, J. W. (1993). Long-term cost of reproduction with and without accelerated senescence in Callosobruchus maculatus: Analysis of age-specific mortality. Evolution, 47, 1302-1312.

Tucić, N., Gliksman, I., Šešlija, D., Milanović, D., Mikuljanac, S., \& Stojković, O. (1996). Laboratory evolution of longevity in the bean weevil (Acanthoscelides obtectus). Journal of Evolutionary Biology, 9, 485-503.

Tucić, N., Šešlija, D., \& Stankovic, V. (2004). The short-term and long-term effects of parental age in the bean weevil (Acanthoscelides obtectus). Evolutionary Ecology, 18, 187-201.

Tucić, N., Stojković, O., Gliksman, I., Milanović, D., \& Šešlija, D. (1997). Laboratory evolution of life-history traits in the bean weevil (Acanthoscelides obtectus): The effects of density-dependent and agespecific selection. Evolution, 51, 1896-1909.

Van Voorhies, W. A. (2002). The influence of metabolic rate on longevity in the nematode Caenorhabditis elegans. Aging Cell, 1, 91-101.

Van Voorhies, W. A., Khazaeli, A. A., \& Curtsinger, J. W. (2003). Long-lived Drosophila melanogaster lines exhibit normal metabolic rates. Journal of Applied Physiology, 95, 2605-2613.

Van Voorhies, W. A., Khazaeli, A. A., \& Curtsinger, J. W. (2004). Testing the "rate of living" model: Further evidence that longevity and metabolic rate are not inversely correlated in Drosophila melanogaster. Journal of Applied Physiology, 97, 1915-1922.

Van Voorhies, W. A., \& Ward, S. (1999). Genetic and environmental conditions that increase longevity in Caenorhabditis elegans decrease metabolic rate. Proceedings of the National Academy of Sciences, 96, 11399-11403.

Vogt, J. T., \& Appel, A. G. (1999). Standard metabolic rate of the fire ant, Solenopsis invicta Buren: Effects of temperature, mass, and caste. Journal of Insect Physiology, 45, 655-666.

Wightman, J. A. (1978). The ecology of Callosobruchus analis (Coleoptera: Bruchidae): Energetics and energy reserves of the adults. Journal of Animal Ecology, 47, 131-142.

Wikelski, M., Spinney, L., Schelsky, W., Scheuerlein, A., \& Gwinner, E. (2003). Slow pace of life in tropical sedentary birds: A common-garden experiment on four stonechat populations from different latitudes. Proceedings of the Royal Society of London B: Biological Sciences, 270, 2383-2388.

Willmer, P., Stone, G., \& Johnston, I. (2009). Environmental physiology of animals. Oxford, UK: Blackwell.

\section{SUPPORTING INFORMATION}

Additional Supporting Information may be found online in the supporting information tab for this article.

How to cite this article: Arnqvist G, Stojković B, Rönn JL,

Immonen $\mathrm{E}$. The pace-of-life: A sex-specific link between metabolic rate and life history in bean beetles. Funct Ecol. 2017; 31:2299-2309. https://doi.org/10.1111/1365-2435.12927 